This document is the preprint version of a published work that appeared in final form in Journal of Molecular Structure, after peer review and technical editing by the publisher. To access the final edited and published work, see https://doi.org/10.1016/j.molstruc.2019.03.024

\title{
The dangers of citing papers you did not read or understand
}

Marco van de Weert ${ }^{1,{ }^{*}} \&$ Lorenzo Stella ${ }^{2, *}$

${ }^{1}$ Department of Pharmacy, Faculty of Health and Medical Sciences, University of Copenhagen.

Universitetsparken 2, 2100 Copenhagen, Denmark

$+4535336186$

Marco.vandeweert@sund.ku.dk

${ }^{2}$ Department of Chemical Science and Technologies, University of Rome Tor Vergata. Via della Ricerca Scientifica 1, 00133 Rome, Italy

+39-06-7259-4463

stella@stc.uniroma2.it

* Authors for correspondence 


\section{Dear Editors,}

Newton famously remarked in a letter to Robert Hooke "If I have seen further it is by standing on ye sholders of Giants" [1] to illustrate that we build further on the foundations laid by our predecessors.

With this in mind we write this letter in response to a recently published paper in this journal, entitled "Characterization of the binding and conformational changes of bovine serum albumin upon interaction with antihypertensive olmesartan medoxomil" [J. Mol. Struct. 2019, Volume 1197, pp. 269-277]. It is unfortunate that this paper passed peer review, as we believe it contains numerous fundamental issues in the methodology, which we and co-workers have discussed in two prior papers, notably published in this journal $[2,3]$. However, more serious is that the authors, in support of an equation, cite prior work that explicitly rejects it as suitable for the task. Specifically, the authors write that "The number of binding sites $(n)$ and the binding constant $(K)$ is obtained ${ }^{27,28}$ from the formula (6)". Formula 6 from their paper is reproduced below:

$$
\log \frac{F^{0}-F}{F}=\log K+n \log [O L M]
$$

Reference 27 is one of those earlier referenced papers written by us [2], where we show with examples that there are numerous pitfalls in the use of this double log equation ("formula (6)" above), and that this particular equation in principle does not determine the number of binding sites. We were rather explicit about this, stating that "[the double log equation] does not yield information on the binding stoichiometry". Rather, " $n$ is just a phenomenological parameter (the Hill coefficient), which is lower than the real number of binding sites... if the hypothesis of "infinite" cooperativity is not satisfied" [2]. Importantly, this point is well established in the literature [4-6]. 
Unfortunately, this is not the first time that our article is cited while ignoring most of its actual content. According to Web of Science [7], our article has been cited 204 times as of December 5, 2018 (and excluding Bagoji et al). Many of these citing papers actually contain several of the methodological mistakes we so strongly criticized. To us this suggests that many of the citing authors have not read our article in sufficient detail, or did not understand it. In connection to the double log equation alone, we found seven more publications that inappropriately cite our paper unequivocally and directly in support of their use and/or interpretation of the double log equation in terms of the number of binding sites [8-14]. We do note that one of these articles, upon our request, has been corrected, in the sense that the inappropriate reference to our work in support of the double log equation has been removed [14].

We would also like to place this case of inappropriate citation of the literature in a broader context, as it is likely far more common than we, as scientists, would like to admit. For example, in 2009 Britta Stordal [15] lamented that despite writing a paper explicitly aimed at dispelling a claim, several publications cited it as supportive of that claim. A slightly different form of inappropriate citations is narrated by Simmons et al [16], who noted that their paper on "False-Positive Psychology" was often cited in connection with only one of the four disclosure requirements they proposed, in the process likely ignoring several of the other requirements mentioned. That inappropriate citation practices can have a significant impact on the subsequent literature is shown by Wetterer [17] and Harzing [18,19]. Wetterer [17] explains how quotation error and subsequent citation copying have led to a persistent, but false, claim of ant extinctions on the island of Madeira, supposedly as a result of an(other) invasive ant species. A similar issue is discussed by Harzing [18,19], who also provides a list of guidelines on proper citation practices [19] and describes how these have been violated in the literature on expatriate failure. These examples all show that improper citation practices, including citing papers that actively contradict the claim for which it is cited, is a widespread problem across multiple fields in 
science. They also show that such errors in scientific rigor have clear consequences, leading to the perpetuation of false information unsupported by the predecessors on whose shoulders one claims to stand. It is therefore no surprise that Miguel Roig, in a writing guide hosted on the website of the Office of Research Integrity (ORI) of the US Department of Health and Services, refers to "citing sources that were not read or thoroughly understood" as a questionable writing practice [20]. Like Stordal [15], we would therefore like to urge the scientific community to go back to first principles and assure, at the very least, that the papers we cite indeed fully support the statement we make. Without this due diligence, citations become meaningless.

\section{References}

[1] I. Newton, Letter to Robert Hooke dated February 5, 1675 (February 15, 1676 in the modern calendar). A facsimile of the letter is available at https://digitallibrary.hsp.org/index.php/Detail/objects/9792 (accessed February 18, 2019).

[2] M. van de Weert \& L. Stella. Fluorescence quenching and ligand binding: A critical discussion of a popular methodology. J Mol Struct 998 (2011) 144-150. https://doi.org/10.1016/j.molstruc.2011.05.023

[2] S. Bobone, M. van de Weert \& L. Stella. A reassessment of synchronous fluorescence in the separation of Trp and Tyr contributions in protein emission and in the determination of conformational changes. J Mol Struct 1077 (2014) 68-76. https://doi.org/10.1016/j.molstruc.2014.01.004

[4] L.I. Grossweiner. Note on the analysis of ligand binding by the 'double-logarithmic' plot. J Photochem Photobiol B 58 (2000) 175-177. https://doi.org/10.1016/S1011-1344(00)00113-5

[5] M.L. Coval. Analysis of Hill Interaction coefficients and the invalidity of the Kwon and Brown equation. J Biol Chem 245 (1970) 6335-6336.

[6] J.N. Weiss. The Hill equation revisited: uses and misuses. FASEB J 11 (1997) 835-841. https://doi.org/10.1096/fasebj.11.11.9285481 


\section{[7] http://www.webofknowledge.com}

[8] G. Sekar, A. Sivakumar, A. Mukherjee \& N. Chandrasekaran. Probing the interaction of neem oil based nanoemulsion with bovine and human serum albumins using multiple spectroscopic techniques. J Mol Liq 212 (2015) 283-290. https://doi.org/10.1016/i.molliq.2015.09.022

[9] C. Chung, T. Rojanasasithara, W. Mutilangi \& D.J. McClements. Enhanced stability of anthocyanin-based color in model beverage systems through whey protein isolate complexation. Food Res Int 76 (2015) 761-768. https://doi.org/10.1016/i.foodres.2015.07.003

[10] J. Yang, L. Qu, W. Yang, Y. Huang, N. Jiao, W. Zhan, D. Zhao \& L. Cui. Interaction of hyperoside with human serum albumin and effect of glucose on the binding. J Spectrosc (2014) Article ID 386586, 9 pages. http://dx.doi.org/10.1155/2014/386586

[11] N. Guo, C. Wang, C. Shang, X. You, L. Zhang \& W. Liu. Integrated study of the mechanism of tyrosinase inhibition by baicalein using kinetic, multispectroscopic and computational simulation analyses. Int J Biol Macromol 118A (2018) 57-68. https://doi.org/10.1016/j.ijbiomac.2018.06.055

[12] C.R. Camargo, Í.P. Caruso, S.J.C. Gutierrez, M.A. Fossey, J.M.B. Filho \& M.L. Cornélio. Spectral and computational features of the binding between riparins and human serum albumin. Spectrochim Acta A 190 (2018) 81-88. https://doi.org/10.1016/i.saa.2017.08.068

[13] K.B. Uppuluri, K.B.A. Ahmed, A. Jothi \& A. Veerappan. Spectrofluorimetric and molecular docking investigation on the interaction of 6-azauridine, a pyrimidine nucleoside antimetabolite, with serum protein. $J$ Mol Liq 219 (2016) 602-607. https://doi.org/10.1016/i.molliq.2016.02.102

[14] J-H. Ye, E. Thomas, L. Sanguansri, Y-R. Liang \& M.A. Augustin. Interaction between whole buttermilk and resveratrol. J Agric Food Chem 61 (2013) 7096-7101. https://doi.org/10.1021/jf401784z

[15] B. Stordal. Citations, citations everywhere but did anyone read the paper? Colloids Surf B 72 (2009) 312. https://doi.org/10.1016/j.colsurfb.2009.04.001 
[16] J.P. Simmons, L.D. Nelson \& U. Simonsohn. False-Positive Citations. Perspect Psychol Sci 13 (2018) 255-259. https://doi.org/10.1177\%2F1745691617698146

[17] J.K. Wetterer. Quotation error, citation copying, and ant extinctions in Madeira. Scientometrics 67 (2006) 351-372. https://doi.org/10.1556/Scient.67.2006.3.2

[18] A-W.K. Harzing. The persistent myth of high expatriate failure rates. Int J Hum Resour Man 6 (1995) 457475. https://doi.org/10.1080/09585199500000028

[19] A-W.K. Harzing. Are our referencing errors undermining our scholarship and credibility? The case of expatriate failure rates. J Organiz Behav 23 (2002) 127-148. https://doi.org//10.1002/job.125

[20] https://ori.hhs.gov/sites/default/files/plagiarism.pdf, accessed February 18, 2019 